\title{
International Experience of Environmental Pollution Liability Insurance
}

\author{
Huilan Guo ${ }^{1}$ \\ ${ }^{1}$ School of Economics, Northwest University for Nationalities, Lanzhou, China \\ Correspondence: Huilan Guo, School of Economics, Northwest University for Nationalities, Lanzhou, China.
}

Received: December 6, 2015

Accepted: January 4, $2016 \quad$ Online Published: February 11, 2016

doi:10.5430/jms.v7n1p59

URL: http://dx.doi.org/10.5430/jms.v7n1p59

This work was supported by the Fundamental Research Funds for the Central Universities of Northwest University for Nationalities (Grant No.31920150117).

\begin{abstract}
The pilot work of environmental pollution liability insurance in China restarted in 2007, and it was less than ten years until now. The pilot provinces and cities did a lot of useful attempts, but it was still in a "Best Game No One Played" embarrassing situation in many places. Based on these above, this paper reviewed the development course of representative national environmental pollution liability insurance like the United States, France and Germany, and hope that it can provide some helpful reference for the improvement of the insurance of China.
\end{abstract}

Keywords: environmental pollution liability insurance, international experience

\section{Introduction}

In recent years, China's rapid economic development is notable, but the extensive growth is often at the expense of environmental pollution in many places. This will cause a lot of bad consequences. For instance, the remediation of environmental pollution need to spend a lot of time and energy, and many polluting enterprises can' $t$ afford the huge amount of property damage and personal injury. So the consequences are often borne by the government. Developed countries in Europe and America have also experienced this situation, they tried many ways to transfer environmental risks and finally most of them chose to establish the environmental pollution liability insurance system since the middle of last century, which is able to compensate the victims in time and reduce the financial pressure of the government. This is a sharp contrast to China. We had a failed attempt in the last century, then restarted the pilot program until 2007. Considering the problems exposed in these years, we have the necessary to learn these international advanced experience to improve the development of environmental pollution liability insurance.

\section{The Present Situation of China's Environmental Pollution Liability Insurance}

China had already tried to begin the environmental pollution liability insurance pilot work early in the last century. The frequent occurrence of environmental pollution accidents forced people urgently to find an effective way to disperse the environmental risk. So Dalian, Shenyang and other places have had a try at the pilot work of environmental pollution liability insurance since 1991. However, the number of insured companies was too small, such as Dalian City only had a total of 15 enterprises insured in four years, Shenyang City had a total of 10 companies in two years. Soon environmental pollution liability insurance was out of sight of people.

After entering the new century, as China's economy continued to develop rapidly, environmental pollution accidents occur more frequently. The China Insurance Regulatory Commission and the Ministry of environmental protection had carried out a series of research on whether or not to resume the work of environmental pollution insurance. After the investigation, the pilot work restarted in 2007. The pilot provinces and cities made many beneficial attempts at developing the environmental pollution liability insurance, but the existence of many obstacles still restricted the development of it, such as insurance awareness of the enterprises, product range, promoting measures and voluntary insurance mode etc.. The pilot's effect is not satisfactory. The government and insurance companies did a lot of work to seek more effective ways to promote. Subsequently, the Ministry of environmental protection and the China Insurance Regulatory Commission jointly issued the guidance on the development of compulsory environmental pollution liability insurance pilot work on January 21, 2013. The guidance proposed to implement the environmental 
pollution liability insurance in the compulsory way and clarified the scope of the pilot enterprises. According to this guidance, Suzhou City, Wuxi city and other places established a model of development with local characteristics, the number of insured companies increased year by year, and some useful promoting measures have been put in place. But in general, the limitations of the legal norms, technology, and the development model still exist. Compared to the development of other countries, the gap is still large. If we don't make improvements, it's still difficult to really play the role of environmental pollution liability insurance in a short term.

\section{A Comparison of the Methods of Promoting Environmental Pollution Liability Insurance in Developed Countries}

In the process of promoting the environmental pollution liability insurance in developed countries, according to their own national conditions, they choose many different ways and formed different development models finally, such as France's voluntary liability insurance model, America's compulsory liability insurance model, Germany's liability insurance combined with guarantee system or financial security model.

Researching on the process of the three representative countries, we can find out the development of the environmental pollution liability insurance follows the general development law of things that anything is growing from scratch, and gradually expanding. But anyway the country must choose a suitable way to develop it by degrees in accordance with legislation, law enforcement, the smooth of implementation and so on. This is very helpful to perfect China's environmental liability insurance.

\subsection{The Voluntary Liability Insurance Mode}

\subsubsection{The Content of This Mode}

In addition to risk must be insured according to the legal provisions, this mode gives both insurance companies and polluting enterprises freedom to choose whether to underwrite or buy environmental pollution liability insurance. The insurance relationship was voluntary to establish under the principle of equality. Representatives of countries such as Britain and France have chosen this mode.

France had no special environmental pollution liability insurance until 1960s. But the insurance companies didn't completely rule out the environmental risk, they provided the necessary protection through general liability insurance if the enterprises will face the risk of sudden water pollution, air pollution. This situation wasn't changed until 1977. The Pollution Reinsurance consortium in France was jointly organized by French and foreign insurance companies. It began to cover pollution in particular insurance policies, including the exceptional risk - oriented enterprises under Hazardous facilities Control Act and special risk insurance for victims. Since then, the responsibility of environmental pollution liability insurance was not only accidental, but also began to include the environmental damage caused by repeated and continuous accidents. In addition, due to France's accession to International Convention on Civil Liability for Oil Pollution Damage compensation in 1969, becoming a member of International Convention on the Establishment of an International Fund for Compensation for Oil Pollution Damage in 1971, France must comply with the relevant provisions of the two conventions relating to oil damage compensation. Therefore, the "French environmental law" enacted on May 27, 1998 enforced to cover oil damage in the compulsory liability insurance system.

\subsubsection{The Evaluation of This Mode}

France and other countries can choose this kind of flexible approach on the basis of a very high awareness of insurance of local enterprises. These enterprises pay great attention to the liability insurance, so these countries can use the insurance practices replace the legislation methods to promote the development of environmental pollution liability insurance. The laws only enforce high-risk enterprises to buy compulsory environmental liability insurance to insure those high-risk enterprises can't evade the responsibility of compensation because of a limited capacity. This mode increases the smoothness of the process in law enforcement and gives the insurance industry more autonomy, reducing the friction between the market and government.

\subsection{The Compulsory Liability Insurance Model}

\subsubsection{The Content of This Mode}

America's environmental pollution liability insurance started early and become a representative of the countries using this model. So many countries have imitated the United States in the establishment of this model. The process of promoting compulsory liability insurance in America is generally divided into the following stages.

The United States didn't have independent environmental pollution liability insurance products before 1966, mainly because the environmental risk hasn't been clearly revealed at that time, only a small number of sudden 
environmental pollution cases happened. So in this period, the damage of environment pollution was usually covered by the insurer with the public liability insurance policy.

The main feature of 1966-1973 stage was that the problem of environmental pollution was beginning to appear and the corresponding disputes were increasing. Although there weren't special environmental pollution liability insurance products still, the public liability insurance didn't exclude the growing environmental risk, even expanded the coverage of the insurance policy, began including the compensation liability caused by continuing or progressive pollution.

The problem of environmental pollution has been more serious since 1973. The number of relevant litigation cases increased rapidly and the cost of compensation also began to grow. In this case, the insurance company's public liability insurance was unable to bear such a large compensation liability, so they began to narrow the scope of insurance liability, and no longer assume the responsibility caused by deliberate or progressive pollution accident. At the same time, the insurance companies have developed an independent environmental pollution liability insurance product, and hoped that the polluting enterprises can choose this new product to disperse the environmental risks which they faced. Furthermore, the government stepped up efforts to curb environmental pollution. They increased the legislative control efforts, promulgated the "Clean Water Act" and the "Comprehensive Environmental Response, Compensation, and Liability Law" and a series of relevant environmental protection laws and regulations. They also established a severe punishment system, required the environmental pollution enterprises pay monetary compensation or subject to criminal sanctions and other. But that would make some companies that have no intention to cause pollution bankrupt easier because of the high fines or huge damages. Predictably, sewage companies need to transfer the huge risk in a proper way. Therefore, in order to solve the contradiction between insurance companies can't continue to use the public liability insurance to cover the environmental risk and sewage companies need to transfer risk, environmental pollution liability insurance became as an independent product in the insurance market of United States since the end of seventy's last century.

America's special insurance group---the Environmental Protection Insurance Company was established in 1988 and underwrite the first insurance policy in July of the same year. The maximum amount of liability limits was a million dollars, the extent specifically included the responsibility of compensation, clearing costs and third party liability taking by insured companies due to sudden, accidental or gradual pollution accident. In the year that followed, the insurance companies of United States plus a finite extension endorsement of pollution liability in a comprehensive general liability insurance, so the responsibility of environmental pollution liability insurance expanded, began to include the work place and operation process of the insured. Since then, polluting enterprises can freely choose two independent insurance policies -"limited liability insurance" and "pollution liability insurance".

America's environmental liability insurance developed better and better in the next 50 years, gradually formed the compulsory liability insurance model. Toxic substances production enterprises must be insured in the environmental liability insurance. Meanwhile, the pollution losses caused by waste disposal must be handled by compulsory liability insurance. Correspondingly, environmental pollution liability insurance products wouldn't remain intact, in contrast, the product variety is more abundant, including product liability insurance, comprehensive general liability insurance, commercial liability insurance and environmental damage liability insurance. But the development of the system in the United States wasn't straightforward. It encounter waves and bumpy. First, the pressure from the court case can't be ignored, because the case will become the main basis for resolving environmental disputes over a long period of time. So many insurance companies took over the unbearable huge compensation liability that were higher than expected, usually because the exemption clause of the insurance contract can't be performed in accordance with the judicial interpretation by court under the principle"public interest is higher than the agreement on the text". The latter law permits the polluting enterprises shall be traced back to afford the clean-up expenses of the place where was once polluted even if they are engaged in lawful business activities. In this case, the insurance companies operating environmental pollution liability insurance were facing greater uncertainty, which was likely to take a huge potential liability. So it's not hard to imagine that the crisis burst in the United States' environmental pollution liability insurance industry in the end of 1980s. Most insurance companies will not provide new environmental pollution liability insurance policy, and even began to increase the premium number of previous policies and reduce the maximum amount of compensation. The number of companies continues to buy the environmental pollution liability insurance was less and less, while the supply side was very few, and insurance companies generally only provide limited compensation products. The new payment limit was constantly added to old insurance policies which had been sold in the market, the market participation rapidly declined. But no matter how, a sound insurance market is very necessary, otherwise the victims and the taxpayers will face the risk of compensation. As a result, some insurance companies have begun to cover certain specific risks in recent years, and the situation of the insurance 
market is gradually improving.

\subsubsection{The Evaluation of This Mode}

Environmental pollution liability insurance in the United States has experienced the process from general to professional, from fully voluntary to compulsory, from underwriting of sudden pollution progressively extended to gradually pollution.In this process, the first consideration is how serious the environmental pollution was. When pollution accidents didn't happen frequently, they used the general liability insurance to cover the risk. Once the pollution was gradually increased, especially the gradual pollution began to appear and the dispute began to accumulate, they expanded the underwriting scope of general liability insurance. Due to the environmental problem wasn't serious enough to require government intervention, it was still solved in accordance with market rules.

With the development of economy, the amount of the compensation amount was increasing rapidly, so the insurance companies began to narrow down the scope to reduce the risk of huge payments, and they all expected that the insured companies can choose the special environmental pollution liability insurance products. At the same time, the government began to take responsibility for their own to protect the environment, increased the penalties for polluting enterprises, strengthened the law enforcement efforts, forced companies to transfer their own risk through insurance. In this situation, the specialized insurance company was established, and the scope of the products was expanded. Although later in the development, because the legislation is too harsh, the development of environmental pollution liability insurance was affected by certain restrictions, but the determination of environmental protection of the United States is unshakable, the business developed in the continuous adjustment and continued to play its role that can't be ignored. This is very important for the development of environmental pollution liability insurance in China. It is well known that after the failure of the pilot in the 1990s, the insurance companies and insured companies have experienced a certain psychological frustration. In recent years, since the new pilot began, we need to adjust the development mode actively to meet the difficulties, so that environmental pollution liability insurance can play its role in China's social construction.

\subsection{The Liability Insurance Combined with Guarantee System or Financial Security Model}

\subsubsection{The Content of This Mode}

Germany is a representative country of using this model. It can be said that Germany's emphasis on environmental protection is higher than most countries. This country did a lot to prevent environment. For example, they made extremely strict environmental standards, established a quite perfect legal system (known as the "most green environmental law"), devote a variety of high-tech to environmental causes. In the process of strengthening environmental protection, Germany has chosen a very radical way to establish the system of environmental pollution liability insurance, which has a profound impact on the rest of Europe.

Germany's insurance companies didn't cover the loss caused by the gradual pollution before 1965. The scope of insurance liability has begun to slowly expand since 1965 but it only covered damage compensation liability caused by water gradual pollution at the beginning. And this state lasted until 1978. After this year, the underwriting scope of insurance companies began to cover the air, water pollution damage compensation liability, but which didn't include the extraterritorial pollution. In order to ensure that the enterprises had specific facilities can fulfill their obligations before the compulsory system was established, Germany ruled the enterprises must adopt the following three measures: the first one is that the enterprises must sign insurance contract with the insurance company that have the right to operate this business, the second one is that the federal government or state government exempt the enterprise's compensation obligations, or insure the enterprise can fulfill this obligation, the third one is that the enterprises can get guarantee or financial security from financial institutions. If these relevant enterprises don't fulfill their obligations according to the provisions of the regulations, not only their facilities will be completely or partially banned to continue to operate, the responsible person must bear one year of imprisonment or fines of criminal liability. Taking into account that some of the outage facilities caused a special risk, these companies should continue to take appropriate measures in accordance with the orders of the competent authorities, the time limit often was less than 10 years. But in practice, banks and other financial institutions weren't actively involved in the financial guarantee, only compulsory liability insurance played its actual role. Then in order to ensure that victims can promptly get compensation, Germany began to implement compulsory environmental pollution liability insurance, provided that enterprises that have a specific facility must be insured since 1991 .

\subsubsection{The Evaluation of This Mode}

Germany's radical development approach is mainly based on the government's determination to protect the environment. From the view of comprehensiveness of law or the implementation efforts, German government has 
firmly put environmental protection in the first place. Although this mandatory approach may cause some of the polluting enterprise's dissatisfaction, but it has been proved that the situation of environmental pollution has been greatly curtailed.

\subsection{Conclusion of the Three Modes}

Different models need different domestic resources and conditions. The mandatory way need to ensure that the government has strong enough implementations and can ease the friction between the insurance companies and law enforcement, and the insurance market can bear the accumulation of all environmental risk. The voluntary way can reduce the friction between government and market, but if some enterprises didn't buy the insurance and can't afford the consequence after the risk happened, the government must solve the difficulties. The voluntary supplement with compulsory way will be limited to the ability to pay and insurance awareness, this isn't easy to control the enthusiasm of sewage companies. But the advantages is giving the insurance industry more freedom.Comparing of these three ways, they all have advantages and disadvantages. But one thing can't be ignored, the world's environmental problems have been gradually highlighted, the system from the voluntary insurance to compulsory insurance is becoming more and more obvious.

\section{The Enlightenment of Promoting Environmental Pollution Liability Insurance in China}

From the above analysis, we can see that the choice of methods of promoting environmental pollution liability insurance is not simple. There are a lot of things to consider like the current law enforcement efforts, the degrees of environmental pollution, the development level of insurance market, the corporate attitudes and tolerance and so on. The pilot in China has experienced the process from voluntary to a combination of voluntary and compulsory. But given the severity of environmental pollution, we should confirm that the compulsory mode is the final trend. But considering environmental protection awareness and insurance awareness in many companies are relatively poor, we should gradually adjust it suited to the situation.

In addition, after summarizing the development path of these countries, we need to take the following measures to perfect environmental pollution liability insurance in China.

\subsection{Perfecting the Legal System}

No matter which way to choose, legal guarantees are indispensable. But this happens to be an obstacle exposed in the pilot in China. Especially now, insurance companies, the public, polluting enterprises are all in the need of legal protection. Otherwise, the insurance companies may face all kinds of risk that can't afford, and then choose to withdraw from the environmental pollution liability insurance market. Public damaged in pollution accident can't get timely and adequate compensation. And polluting enterprises may bankrupt because of lots of compensation. So most countries have provided substantial legal support like the United States and Germany. So we should perfect the legal system to ensure the development of environmental pollution liability insurance.

\subsection{Choosing the Appropriate Underwriting Institutions}

The specialized insurance agency of the United States has a high degree of specialization and credibility. It can protect the victim to obtain full compensation under the compulsory insurance. France's pollution reinsurance consortium will spread the environmental risk in various insurance companies. Another number of countries like China don't have a special insurance agency, the insurance market freedom is very high. But many insurance companies don't want to provide these products because of high risk. In order to promote its development, we should carefully consider that what kind of insurance organizations is more suited to the situation of China.

Expanding the Coverage of Products

Although the process isn't the same in those countries, the scope of the environmental pollution liability insurance products is gradually expanding. Due to lack of experience and technology, insurance companies in the initial only underwrite non intentional and sudden environmental pollution accident. After years of accumulation, the insurance market is gradually mature, and the underwriting scope is also extended to the cumulative pollution damage. Summary of present situation of environmental pollution liability insurance product in China, none of the category or coverage of product is quite satisfactory. In order to enhance the attractiveness of environmental pollution liability insurance and meet the needs of environmental protection, we should develop the new varieties of this product, for example, the insurance companies try to research and choose the right moment to sell the product covered the gradual contamination.

\section{A Conclusion}

The development of environmental pollution liability insurance in China has experienced twists and turns. But 
China's confidence to protect the environment is not shaken. In order to avoid detours, we should learn from the other countries seriously.

Unfortunately, considering environmental risk is very complex and environmental pollution liability insurance has a strong practical operation, I still have many shortcomings in current research because of limited practical experience. Some important problems such as reinsurance support will be studied in follow-up research.

\section{References}

Wang, N. (2015, June). Comparison and Reference of the environmental liability insurance system in developed countries. Knowledge Economy.

Yang, L. Z., \&Liu, Y. (2005, November). The United States environmental pollution liability insurance system to examine and Revelation. Law Journal.

You, G. Y. (2009). Environmental pollution liability insurance model selection and pricing research. Ocean University of China.

You, G. Y., \& Zhang, L. Q. (2008, February). Comparison and Revelation of environmental pollution liability insurance system of the western countries. Shanghai Insurance. 